\title{
KELAYAKAN FINANSIAL AGROINDUSTRI TERASI DI DESA AMBUNTEN TIMUR KECAMATAN AMBUNTEN KABUPATEN SUMENEP
}

\section{FINANCIAL FEASIBILITY OF TERASI AGROINDUSTRY IN EAST AMBUNTEN VILLAGE, AMBUNTEN DISTRICT, SUMENEP DISTRICT}

\author{
Fatmawati $^{1}$, Bambang Hermanto ${ }^{2}$, Moh. Kurdi $^{3}$ \\ ${ }^{1}$ Program Studi Agribisnis, Fakultas Pertanian, Universitas Wiraraja, \\ ${ }^{2.3}$ Program Studi Manajemen, Fakultas Ekonomi dan Bisnis, Universitas Wiraraja, Jl. Raya \\ Sumenep - Pamekasan KM. 5 Patean Kabupaten Sumenep, Jawa Timur, Indonesia \\ fatmawati.ir@gmail.com, bambang@wiraraja.ac.id, kurdi.em@gmail.com
}

\begin{abstract}
ABSTRAK
Potensi perikanan yang dimiliki Kabupaten Sumenep sangatlah besar dan menjanjikan. Hal ini kemudian di Desa Ambunten Timur Kecamatan Ambunten sebagian masyarakat memanfaatkan potensi perikanan tersebut sebagai produk, diantaranya petis, ikan asin, ikan asap dan terutama terasi. Usaha terasi yang ada di Desa Ambunten Timur belum pernah dilakukan analisis, sehingga perlu adanya penelitian ini dilakukan. Metode dalam penelitian ini menggunakan analisis kelayakan dan analisis finansial. Hasil dari penelitian ini adalah: biaya produksi sebesar (TC) Rp. 37.771.568,- pendapatan agroindustri terasi ( $\pi$ ) sebesar Rp. 18.489.543,- dan efisiensi (R/C Ratio) agroindustri terasi sebesar Rp. 1.49,-. Dari ketiga kriteria.
\end{abstract}

Kata kunci:Finansial; Efisiensi; Agroindustri; Terasi

\section{ABSTRACT}

The fishery potential of Sumenep Regency is huge and promising. In this case, in Ambunten Timur Village, Ambunten Subdistrict, some people use the fishery potential as a product, including petis, salted fish, smoked fish and especially shrimp paste. The shrimp paste business in Ambunten Timur Village has never been analyzed, so this research needs to be done. The method in this study uses a feasibility analysis and financial analysis. The results of this study are: production costs of (TC) Rp. 37,771,568, - shrimp paste agro-industry income $(\pi)$ of $R p$. 18,489,543, - and the efficiency ( $R / C$ Ratio) of the shrimp paste agroindustry of Rp. 1.49, -. Of the three criteria.

Keywords: Financial; Efficiency; Agro industry; Shrimp paste

\section{Pendahuluan}

Indonesia merupakan negara maritim yang kaya sumber kelautan. Di Indonesia sektor kelautan dan perikanan mempunyai peranan yang sangat penting dalam membangun perkonomian nasional. Selain menyediakan bahan pangan bagi penduduk, sektor ini juga menyumbangkan devisa serta menyediakan kesempatan kerja dan bahan baku bagi industri. Oleh karena itu sangatlah penting memperhatikan pembangunan di bidang kelautan dan perikanan.

Wilayah pesisir dan laut Indonesia mempunyai potensi yang cukup tinggi. Potensi tersebut meliputi : (a) Sumber daya yang dapat diperbaharui seperti perikanan (tangkap, budidaya, dan pasca panen), hutan mangrove, terumbu karang, industri bioteknologi kelautan dan pulau-pulau 
kecil, (b) Sumber daya yang tidak dapat di perbaharui seperti minyak bumi dan gas, bahan tambang dan mineral lainnya serta harta karun. (c) Energi kelautan seperti : pasang surut, gelombang angin, OTEC (Ocean thermal energy convertion). (d) Jasa-jasa lingkungan seperti : pariwisata, perhubungan dan pelabuhan serta penampung limbah (Dahuri, 2001 dalam Kurdi 2010).

Keanekaragaman biota laut yang ada di Indonesia mempunyai keunggulan kompetitif yang tidak dimiliki oleh negara lain sehingga dapat dibangun industri maritim sebagai penggerak perekonomian nasional. Untuk mengoptimalkan industri berbasis sumber daya ini (resources based industry), dibutuhkan penerapan iptek dan manajemen profesional (Poter 1998 dalam Dahuri, 2002).

Pulau Madura terdiri dari empat kabupaten salah satunya adalah Kabupaten Sumenep yang berada paling ujung timur dengan kabupaten kepulauan terbanyak dibandingkan dengan kabupaten lain yang ada di Wilayah Provinsi Jawa Timur. Kabupaten Sumenep memiliki luas perairan hampir 50 persen dari luas peraian yang ada di Jawa Timur. Dengan luas peraian yang sangat luas tersebut memungkinkan Kabupaten Sumenep untuk melakukan pengembangan dan pemberdayaan pada sektor kelautan dan perikanan.

Pengembangan potensi perikanan laut memiliki potensi yang sangat besar di Kabupaten Sumenep. Sumber daya perikanan yang ada di Kabupaten Sumenep meliputi perikanan laut, air tawar, payau dan perikanan umum. Potensi perikanan laut memiliki peluang yang sangat besar untuk dikembangkan dibandingkan dengan potensi yang lain. Salah satu perikanan laut yang ada di Kabupaten Sumenep terletak di Desa Ambunten Timur. Desa Ambunten Timur yang berada di Kecamatan Ambunten yang dikenal dengan sebagai tempat pengolahan hasil perikanan seperti petis, ikan asin, ikan asap dan terutama terasi.
Melihat dari pengolahan hasil perikanan yang ada hasil pengolahan ikan dalam bentuk terasi sangatlah berpeluang dan memiliki potensi yang sangat besar. Pengolahan terasi memiliki nilai ekonomis yang sangat tinggi. Sampai saat ini pengolahan terasi banyak dilakukan oleh masyarakat di kawasan pesisir sebagai kegiatan sampingan untuk menunjang ekonomi dan pendapatan keluarga. Kondisi tersebut dapat memungkinkan untuk meningkatkan taraf kehidupan masyarakat dengan pengolahan dari hasil sektor kelautan dan perikanan (Zaini, 2018)

Usaha terasi yang adai di Desa Ambunten Timur Kecamatan Ambunten dalam pengembangannya perlu untuk dilakukan evaluasi dan analisis untuk mengetahui tingkat kelayakanan baik secara finansial dan secara efisiensinya demi keberlanjutan usaha terasi. Jadi perlu adanya penelitian untuk memberikan informasi yang tepat kepada pengusaha terasi. Sebab selama ini belum pernah dilakukan analisis terhadap usaha terasi, sehingga pelaku usaha belum dapat mengetahui secara pasti kelayakan dari usaha terasi yang selama ini dijalani. Selain itu, pelaku usaha juga belum mengetahui cara untuk melakukan analisis evaluasi sehingga perlunya peran serta dari perguruan tinggi untuk membantu melakukan evaluasi.

\section{Metode Penelitian}

Metodeyang digunakan dalam penelitian adalah studi kasus pada pelaku usaha terasi yang ada di Desa Ambunten Timur.Responden pada penelitian adalah pelaku usaha terasi yang di Desa Ambunten Timur dengan cara Simple Random Sampling (Malo, 2000).

Jenis data yang digunakan dalam penelitian yaitu data primer dan data sekunder. Analisis data yang digunakan 
dalam penelitian yaitu analisis kelayakan dan analissi finansial

\section{Hasil dan Pembahasan}

Suatu Agroindustri dikatakan menguntungkan apabila pendapatan atau keuntungan yang diperoleh bernilai positif, sebaliknya dikatakan rugi apabila pendapatan yang diperolehnya bernilai negatif. Dalam analisis Agroindustri Terasi komponen-komponennya adalah analisa biaya baik biaya tetap maupun biaya tidak tetap, biaya penerimaaan, keuntungan, dan perbandingan $\mathrm{R} / \mathrm{C}$ ratio sehingga dapat diperoleh gambaran hasil yang signifikan dari Agroindustri Terasi di Desa Ambunten Timur, sebagaiman uraian berikut :

1. Analisa Biaya Tetap (Fixed Cost)

Analisa biaya tetap dilakukan terhadap sewa tanah dan biaya penyusutan peralatan yang terdiri dari timbangan, alat penghancur, tempat fermentasi, perangkat penjemuran, wadah plastic, Kain saring yang mempunyai jangka usia ekonomis kurang dari satu tahun. Dengan demikian dalam Agroindustri Terasi dapat diketahui total biaya tetap (TFC) sebesar Rp 29.569.624,- untuk produksi selama satu tahun.

Table 1. Analisa Biaya Tetap Agroindustri Terasi per Minggu/per Produksi

\begin{tabular}{ccr}
\hline No & Uraian & Jumlah (Rp) \\
\hline 1. & Sewa Gedung & $500.000,-$ \\
2. & Penyusutan peralatan & $83.063,-$ \\
\hline & Total & $\mathbf{5 8 3 . 0 6 3 , -}$ \\
\hline
\end{tabular}

Sumber: Data Primer yang diolah

2. Analisa Biaya variabel (Variable Cost) Pada analisa biaya variabel yang dihitung adalah semua biaya yang dikeluarkan oleh pengusaha selama proses produksi yang habis dipakai dalam satu minggu. Adapun biaya-biaya yang termasuk dalam biaya variabel yaitu sarana produksi dan biaya tenaga kerja. Dalam analisa ini diketahui biaya variabel sebesar Rp 37.771.568,- dalam satu kali proses produksi selama satu minggu, sebagaimana Tabel 2.

\begin{tabular}{ccrr} 
Tabel & 2.Analisa & Biaya & Variabel \\
& Agroindustri & Terasi & per \\
Minggu/per Produksi & & \\
\hline
\end{tabular}

\begin{tabular}{clrr}
\hline No. & \multicolumn{1}{c}{ Uraian } & \multicolumn{1}{c}{$\begin{array}{c}\text { Jumlah } \\
\text { (Rp.) }\end{array}$} & $\begin{array}{c}\text { Prosentase } \\
(\boldsymbol{\%})\end{array}$ \\
\hline 1. & Udang & 30.000 .000 & $79,44 \%$ \\
2. & Garam & 416.194 & $1,10 \%$ \\
3. & Pewarna & 64.948 & $0,17 \%$ \\
4. & Plastik & 208.441 & $0,55 \%$ \\
5. & Tenaga Kerja & 4.983 .889 & $13,24 \%$ \\
6. & Transportasi & 1.600 .000 & $4,24 \%$ \\
7. & Pemeliharaan & 475.000 & $1,26 \%$ \\
\hline
\end{tabular}

$\begin{array}{lll}\text { Jumlah } & \mathbf{3 7 . 7 7 1 . 5 6 8} & \mathbf{1 0 0 , 0 0 \%}\end{array}$

Nampaknya berdasarkan Tabel 2 di atas, biaya variabel yang cukup besar adalah biaya bahan baku yang mencapai $79,44 \%$ dari total biaya variabel, yaitu bahan baku udang.

3. Analisa Total Biaya Produksi (Total Cost)

Total biaya produksi adalah hasil penjumlahan biaya tetap (FC) dengan biaya variabel (RC) yang merupakan keseluruhan biaya yang dikorbankan untuk mencapai jumlah produksi tertentu. Pada analisis Agroindustri Terasi dapat diperoleh total biaya sebesar Rp 38.354.631,- sebagaimana pada tabel 5.

Tabel 3. Analisa Biaya Total Pengusaha Agroindustri Terasi per Minggu/per Produksi

\begin{tabular}{|c|c|c|}
\hline No & Uraian & Jumlah (Rp) \\
\hline 1. & Biaya tetap & $583.063,-$ \\
\hline 2. & Biaya variabel & 37.771.568,- \\
\hline & Total & 38.354.631,- \\
\hline
\end{tabular}

4. Analisa Penerimaan dan Keuntungan

Jumlah produksi dan harga jual merupakan dua faktor yang sangat mempengaruhi nilai dari pada penerimaan suatu usaha sehingga dapat diketahui usaha tersebut untung atau rugi. Penerimaan merupakan hasil kali antara jumlah produksi dengan harga jual per satuan. 
Tabel 4. Analisa Nilai Penerimaan Agroindustri Terasi per Minggu/Sekali Produksi

\section{No. Uraian}

Jumlah

1. Rata-rata Produksi (Kg) 2.250

2. Harga per kilogram (Rp.) 25.000 Penerimaan (Rp.) 56.261.111

Dari hasil analisa usaha Agroindustri Terasi diperoleh nilai penerimanaan sebesar Rp 56.261.111,- per minggu/sekali produksi, sedangkan keuntungan atau pendapatan sebesar Rp 18.489.543,- pada tabel dibawah ini disajikan jumlah penerimaan dan keuntungan.

Tabel 5. Analisa Nilai Keuntungan Agroindustri Terasi per Minggu/Sekali Produksi

\begin{tabular}{llr}
\hline No & \multicolumn{1}{c}{ Uraian } & Jumlah $(\mathbf{R p )}$ \\
\hline 1. & Penerimaan & $56.261 .111,-$ \\
2. & Total biaya & $37.771 .568,-$ \\
\hline & Keuntungan & $\mathbf{1 8 . 4 8 9 . 5 4 3 , -}$
\end{tabular}

Keuntungan 18.489.543,-

5. Analisa R/C Ratio Usaha Agroindustri Terasi

Perbandingan antara total penerimaan (TR) dengan total biaya (TC) merupakan besarnya nilai pendapatan atau keuntungan yang diterima pengusaha untuk setiap rupiah yang dikeluarkan pengusaha, dan hasil ini dapat dijadikan ukuran dalam penilaian tingkat efisiensi industri terasi. Hasil analisa pada penelitian analisis usaha Agroindustri Terasi sebagaimana pada Tabel 6.

Tabel 6. R/C Ratio Usaha Agroindustri Terasi per Minggu/Sekali Produksi

\begin{tabular}{lcr}
\hline No & Uraian & Jumlah \\
\hline 1 & Total penerimaan & $56.261 .111,-$ \\
2 & Total biaya & $37.771 .568,-$ \\
\hline & R/C Ratio & $\mathbf{1 , 4 9 , -}$ \\
\hline
\end{tabular}

\section{Pembahasan}

1. Biaya Produksi Agroindustri Terasi

Biaya tetap (fixed cost) tidak akan berubah walaupun tingkat output yang dihasilkan mengalami perubahan dan biaya tetap akan selalu dikeluarkan setiap melakukan proses produksi. Rata-rata biaya tetap yang dikeluarkan pada Agroindustri
Terasi di Desa Ambunten Timur adalah sebesar Rp 583.063 dan rekapitulasi analisa biaya tetap sebagaimana pada lampiran.

Pada analisa biaya variabel (Variable Cost) Agroindustri Terasi di Desa Ambunten Timur, menunjukkan bahwa responden banyak telah melaksanakan finishing pekerjaan yang baik sehingga hal ini sangat berpengaruh pada produktifitas terasi tersebut walupun ada beberapa responden yang masih belum memenuhi anjuran teknologi pembuatan terasi yang sehat.

Total biaya variabel dari usaha Agroindustri Terasi di Desa Ambunten Timur adalah rata-rata sebesar Rp. 37.771.568,- sebagaimana tertera pada lampiran nampak pada biaya bahan baku merupakan biaya terbesar pada produksi terasi yaitu sebesar 79,44\%, dimana pemenuhannya didatangkan dari luar daerah Kabupaten Sumenep antara lain di Kabupaten Probolinggo, Banyuwangi, Jember, Situbondo, Malang, Pasuruan, dan sekitarnya. Sedangkan bahan baku udang yang berasal dari Sumenep hanya cukup untuk dikonsumsi masyarakat sebagai laukpauk.

Biaya usaha yang dilaksanakan baik usaha dalam skala besar maupun kecil merupakan hal yang harus diperhitungkan karena biaya dapat menentukan sampai sejauh mana keuntungan yang diperoleh dari usaha tersebut, karena akan lebih berguna dalam rangka merencanakan suatu usaha selanjutnya.

Dalam analisis Agroindustri Terasi di Desa Ambunten Timur menunjukkan bahwa biaya total sebesar Rp 37.771.568,-

2. Penerimaan dan Pendapatan Agroindustri Terasi

Nilai penerimaan dari suatu usaha merupakan seluruh output yang dihasilkan dikalikan dengan harga jual per satuan yang berlaku, sebagaimana yang tertera pada tabel menunjukkan bahwa penerimaan per minggu dari Agroindustri Terasi di Desa Ambunten Timur adalah sebesar Rp. 56.261.111,- dan keuntunganan sebesar Rp 
18.489.543,- sebagaimana pada Lampiran

5.

Nilai penerimaan tersebut sudah tinggi hal ini lebih besar antara biaya produksi yang dikeluarkan dengan produktifitas dari pada Agroindustri Terasi yang dikelola pengusaha yang telah dikerjakan sesuai pembuatan terasi yang baik walaupun masih ada yang dalam penggunaan pewarna, pengeringan, dan pengepakan yang masih belum memenuhi anjuran teknologi pembuatan terasi.

Secara umum dalam Agroindustri Terasi di Desa Ambunten Timur dimana lokasi penelitian dilaksanakan dapat dikatagorikan telah dikelola dengan baik, hal ini disebabkan antara lain pengusaha telah banyak yang melakukan pengeringan yang baik dan dosis yang digunakan memenuhi anjuran teknologi pembuatan terasi yang baik yaitu penggunaan garam dan zat pewarna yang baik sehingga rasanya lezat dan warnanya menarik.

3. Efisiensi Agroindustri Terasi

Dari hasil analisa usaha Agroindustri Terasi di Desa Ambunten Timur menunjukkan bahwa $\mathrm{R} / \mathrm{C}$ ratio ratarata per produksi sebesar 1,49. Dengan demikian setiap penggunaan biaya sebesar 1 satuan nilai, maka diperoleh penerimaan sebesar 1,49 satuan nilai, artinya setiap pengeluaran 1 rupiah akan dikembalikan 1,49 rupiah atau dengan biaya total sebesar Rp 37.771.568,- akan dikembalikan sebesar Rp 56.261.111,- sebagaimana tercantum pada lampiran 6. Dengan kata lain, tingkat efisiensi agroindustri terasi dapat diperoleh dari perbandingan antara total penerimaan (TR) dengan biaya total (TC).

Dengan tingkat pengembalian modal sebesar tersebut mengindikasikan bahwa analisis Agroindustri Terasi di Desa Ambunten Timur adalah mempunyai prospek cukup baik sehingga hipotesis pertama analisis Agroindustri Terasi memberikan keuntungan dan efisien (R/C > 1), terbukti dengan demikian akan meningkatkan pendapatan pelaku usaha.

\section{KESIMPULAN}

Berdasarkan hasil penelitian dan pembahasan yang telah diurai di atas, maka dapat ditarik suatu kesimpulan bahwa :

1. Biaya produksi agroindustri terasi di Desa Ambunten Timur sebesar Rp. 37.771.568,- tiap minggu/sekali produksinya.

2. Pendapatan usaha agroindustri terasi di Desa Ambunten Timur sebesar Rp. 18.489.543,- tiap minggu/sekali produksinya.

3. Analisis Agroindustri Terasi di Desa Ambunten Timur memiliki prospek yang cukup baik dan efisien. Hal ini dapat dilihat dari nilai $\mathrm{R} / \mathrm{C}$ ratio ratarata per produksi sebesar 1,49 yang berarti setiap biaya yang dikeluarkan sebesar Rp. 1,- untuk modal produksi akan memberikan keuntungan 1,49.

\section{DAFTAR PUSTAKA}

Adawiyah, R. 2006. Pengolahan dan Pengawetan Ikan. Bumi Aksara. Jakarta.

Dahuri, D. 2002. Membangun Kembali Perekonomian Indonesia Melalui Sektor Perikanan dan Kelautan. LISPI Jakarta

Erta A, Kiki Y, Agus S. 2012. Efisiensi dan Identifikasi Loss pada Roses Pengolahan Terasi Udang Rebon (acetes sp) di Desa Belo Laut Kecamatan Muntok Bangka Belitung. Prodi Teknologi Hasil Perikanan, Fakultas Pertanian, Universitas Sriwijaya. Palembang

Kurdi, M. (2019). Analisis Kelayakan Finansial Usaha Ayam Ras Petelur Di Desa Soddara Kecamatan Pasongsongan Kabupaten Sumenep. JAS (Jurnal Agri Sains), 3(1).

Kurdi, Moh. 2010. Strategi Pengembangan Agribisnis Perikanan Laut di Kabupaten Sumenep. Skripsi Prodi Agribisnis, Fakultas Pertanian, Universitas Wiraraja. Sumenep.

Kurdi, M., \& Fatmawati, F. (2020). Analysis of Efficiency and Added 
Value of Gayam Chips in UD. Harapan Jaya Sumenep Regency. Kampung Jurnal Ilmiah 2020, 31-39.

La Ola L.O. 2014. Efisiensi Biaya Produksi dan Daya Saing Komoditi Perikanan Laut di Pasar Lokal dan Pasar Ekspor. Jurnal Bisnis Perikanan, Vol 1. Nomor 1. Universitas Halu e Leo. Kendari

Malo, 2000. Metode Penelitian Sosial. Universitas Terbuka, Jakarta.

Maulidah, Silvana. 2012. Pengantar Usaha Tani: Kelayakan Usaha Tani. Universitas Brawijaya. Malang.

Nur, Faizal. 2019. Analisis Usaha Agroindustri Terasi Udang Di Desa Meskom Kecamatan Bengkalis Kabupaten Bengkalis. Prodi Agribisnis, Fakultas Pertanian, Universitas Islam Riau. Pekanbaru

Rahardja P. 2008. Pengantar Ilmu Ekonomi. Fakultas Ekonomi Universitas Indonesia. Jakarta.

Siang R.D \& A N. 2010. Pengantar Ekonomi Perikanan. Unhalu Press. Kendari.

Suprapti, M. L. 2002. Membuat Terasi. Kanisius, Yogyakarta.

Solehuddin, Moh. 2008.

Toariaunaldi, Mhd., Hendrik. \& Hamid, H. 2017. Prospek Pengembangan Usaha Terasi di Pelabuhan Perikanan Pantai Kuala Tungkal Kabupaten Tanjung Jabung Barat Provinsi Jambi. Universitas Riau.

Zainal M, Roisatul A. 2018. Analisis Usaha Terasi Udang Di Desa Tambaklekok Kabupaten Pasuruan. Jurnal Teknologi Pangan, Vol 9. Nomor 2. Program Studi Teknologi Hasil Perikanan, Fakultas Pertanian,Universitas Yudharta. Pasuruan 